\title{
COVID-19 with rapid progression to hypoxemia likely due to imbalance between ventilation and blood flow: A case report
}

\author{
Nobuyuki Koriyama ${ }^{1}$, Akihiro Moriuchi ${ }^{1}$, Kensaku Higashi ${ }^{1}$, Tetsuro Kataoka ${ }^{1}$, Takuro \\ Arimizu $^{1}$, Go Takaguchi ${ }^{1}$, Hideki Matsuoka ${ }^{1}$, and Maki Otsuka ${ }^{1}$ \\ ${ }^{1}$ National Hospital Organisation Kagoshima Medical Center
}

July 8, 2021

\begin{abstract}
We experienced a case of COVID-19 with hypoxia, which was presumed to be due to the development of ventilation and blood flow imbalance by pulmonary intravascular coagulopathy or hypoxic pulmonary vasoconstriction. Early, short-term combination therapy with remdesivir, nafamostat mesilate and low-dose dexamethasone was extremely effective.
\end{abstract}

\section{Case Report}

COVID-19 with rapid progression to hypoxemia likely due to imbalance between ventilation and blood flow: A case report

Nobuyuki Koriyama MD, $\mathrm{PhD}^{1}$, Akihiro Moriuchi MD, $\mathrm{PhD}^{2}$, Kensaku Higashi MD ${ }^{3}$, Tetsuro Kataoka MD, $\mathrm{PhD}^{3}$, Takuro Arimizu $\mathrm{MD}^{4}$, Go Takaguchi $\mathrm{MD}^{4}$, Hideki Matsuoka $\mathrm{MD}^{4}$, Maki Otsuka MD, $\mathrm{PhD}^{5}$

${ }^{1}$ Department of Diabetes and Endocrine Medicine, ${ }^{2}$ Gastroenterology, ${ }^{3}$ Cardiology,${ }^{4}$ Cerebrovascular Medicine and ${ }^{5}$ Hematology, National Hospital Organization Kagoshima Medical Center, 8-1 Shiroyama-cho, Kagoshima 892-0853, Japan

\section{Correspondence to:}

Dr. Maki Otsuka

Department of Hematology, National Hospital Organization Kagoshima Medical Center, 8-1 Shiroyama-cho, Kagoshima 892-0853, Japan

Tel: +81-99-223-1151; Fax: +81-99-226-9246;

E-mail:otsuka.maki.we@mail.hosp.go.jp

\section{Abstract}

We experienced a case of COVID-19 with hypoxia, which was presumed to be due to the development of ventilation and blood flow imbalance by pulmonary intravascular coagulopathy or hypoxic pulmonary vasoconstriction. Early, short-term combination therapy with remdesivir, nafamostat mesilate and low-dose dexamethasone was extremely effective.

Key words: COVID-19, hypoxic pulmonary vasoconstriction, pulmonary intravascular coagulopathy, remdesivir, nafamostat mesilate, dexamethasone

\section{Key Clinical Message:}


Early, short-term combination therapy with remdesivir, nafamostat mesilate and low-dose dexamethasone was extremely effective for a case of COVID-19 with hypoxia due to the development of ventilation and blood flow imbalance.

\section{Introduction}

At the end of 2019, an outbreak of atypical pneumonia patients was reported in Wuhan City, Hubei Province, China. This pneumonia was shown to be caused by severe acute respiratory syndrome coronavirus 2 (SARSCoV-2) infection and was named coronavirus disease 2019 (COVID-19). To date, the number of infected people globally is about 140 million, and the number of deaths is about 3 million. It is known that the disease is more likely to become severe in the elderly than in the young, and the mortality rate of people aged 80 years and over is extremely high, at $14.8-20.2 \%(1,2)$. It has also been reported that there is a difference in mortality depending on the presence of underlying comorbidities, with reported mortality rates of $10.5 \%$ in patients with cardiovascular disease, $7.3 \%$ in diabetics, $6.3 \%$ in patients with chronic respiratory disease, and $6.0 \%$ in hypertensive patients (3).

SARS-CoV-2 has a positive-sense, single-stranded RNA genome, and binds to angiotensin-converting enzyme 2 (ACE2) receptors present on the cell surface with a coronal spike protein on its surface envelope. By doing so, it invades the cell by endocytosis due to membrane fusion, leading to viral amplification (4). ACE2 receptors are known to be widely expressed in nerve cells, olfactory nerve epithelium, the tongue, intestinal epithelial cells, vascular endothelial cells, etc., in addition to alveolar type II epithelial cells $(5,6)$. Therefore, SARS-CoV-2 causes not only severe pneumonia and fatal acute respiratory distress syndrome, but also multifaceted disorders of many cells, tissues, and organs (7).

In COVID-19 pneumonia, cases of severe hypoxemia in the early stage (8) and cases of sudden deterioration in respiratory status due to silent hypoxia leading to death (9) have been reported. It is speculated that major changes in one of the following factors: 1) thrombosis due to impaired blood coagulation, 2) disordered hypoxic pulmonary vasoconstriction (HPV) $(10,11)$, and 3 ) imbalance between ventilation and blood flow in healthy lungs, or relatively small changes in these factors occurring at the same time (11) are responsible for the disease severity in such cases.

Here, we report a case of COVID-19 who showed progressive silent hypoxemia that was presumed to be due to an imbalance between ventilation and blood flow, but with only mild pneumonia visualized on computed tomography $(\mathrm{CT})$, in whom early multidrug therapy was effective.

\section{Case Report}

The patient was a 70-year-old Japanese man $\left(172.0 \mathrm{~cm}\right.$ tall, weighing $68.0 \mathrm{~kg}$, body mass index $\left.23.0 \mathrm{~kg} / \mathrm{m}^{2}\right)$ who had smoked 20 cigarettes a day for 47 years until 5 years ago. He was under treatment and follow-up for essential hypertension, dyslipidemia and chronic kidney disease, and his blood pressure and lipid levels were well controlled with administration of $40 \mathrm{mg}$ of olmesartan medoxomil (Olm) and $5 \mathrm{mg}$ of atorvastatin calcium hydrate. His renal function was stable. The patient presented with nasal discharge, malaise and a mild cough, and tested positive for SARS-CoV-2 by the polymerase chain reaction (PCR) test, three days after coming in extended contact with a colleague who was also diagnosed with SARS-CoV-2. Since he had many risk factors for disease aggravation, he was urgently admitted to our hospital (Day 1) the day after symptom onset and confirmation of the diagnosis.

At admission, his body temperature was $36.4{ }^{\circ} \mathrm{C}$, blood pressure was $185 / 72 \mathrm{mmHg}$, pulse was 86 beats $/ \mathrm{min}$, respiratory rate was 20 beats/min and peripheral oxygen saturation on pulse oximetry $\left(\mathrm{SpO}_{2}\right)$ was $97.0 \%$. Laboratory findings at this time showed lymphocyte depletion and coagulation abnormalities [lymphocytes $8.5 \%$, fibrinogen $518 \mathrm{mg} / \mathrm{dL}$, fibrinogen degradation products $5.26 \mu \mathrm{g} / \mathrm{mL}$ and D-dimer (D-D) $1.68 \mu \mathrm{g} / \mathrm{mL}$ ] (Table 1). In addition, iron deficiency anemia was observed (he was scheduled for close examination of the gastrointestinal tract after COVID-19 was cured), and it was difficult to evaluate the ferritin level (Table 1). CT showed emphysematous changes in the lung field and ground-glass-like shadows with unclear borders below the dorsal pleura of the upper right lobe (Figure 1a). 
Although no decrease in $\mathrm{SpO}_{2}$ was observed, administration of favipiravir (Fav) $3600 \mathrm{mg}$ daily was started from the evening of the same day, due to the presence of mild pneumonia as seen on CT and the presence of multiple comorbidities. In addition, since $\mathrm{SpO}_{2}$ was lower than at night, $1 \mathrm{~L} / \mathrm{min}$ oxygen administration via a nasal cannula was also started. Weakness and a decreased level of consciousness (tendency to somnolence) appeared from the early morning of Day 2, but a neurologist ruled out a stroke. Since somnolence and weakness were considered as side effects of Fav, the drug was discontinued on the evening of Day 2, and his symptoms improved by the morning of Day 3. Thereafter, since his temperature increased again, the frequency of administration of acetaminophen $500 \mathrm{mg}$ was increased from 0 to 3 times a day. In addition, his CRP level increased and $\mathrm{SpO}_{2}$ decreased, requiring an increase in oxygen flow rate from 1 to $3 \mathrm{~L} / \mathrm{min}$ by nasal cannula. CT performed on Day 4 showed slight deterioration in the pneumonia (Figure 1b). Therefore, 200 $\mathrm{mg}$ of remdesivir (Rem) was administered on Day 4, with $100 \mathrm{mg}$ daily being administered from Day 5 until Day 10, for a total of 7 days (Figure 2a). On Day 7, blood gas data under administration of $4 \mathrm{~L} / \mathrm{min}$ oxygen by nasal cannula (Figure $2 \mathrm{~b}$ ) showed that the alveolar-arterial oxygen difference $\left(\mathrm{A}-\mathrm{aDO}_{2}\right)$ had increased to $122.1 \mathrm{mmHg}$ (Table 2), indicating an imbalance between ventilation and blood flow. However, no pulmonary hypertension was observed on electrocardiogram or echocardiography. Furthermore, since a tendency of increasing D-D levels was also observed (Figure 2d), the combination of nafamostat mesilate (Naf) $100 \mathrm{mg}$ daily by continuous intravenous infusion and dexamethasone (Dex) $6 \mathrm{mg}$ daily was administered for 4 days from Day 7 (Figure 2a). The treatment was remarkably effective, resulting in fever reduction and a decrease in CRP and D-D levels (Figure 2a, c and d). On Day 10, oxygen administration could be discontinued, and at the same time (Figure 2b), his blood pressure control improved (Figure 2e). By Day 13, A-aDO 2 had also significantly improved to $33.2 \mathrm{mmHg}$ without supplementary oxygen (Table 2), and CT showed a tendency for improvement in pneumonia (Figure 1c).

For blood pressure control during the course of his hospitalization, continuous intravenous infusion of pernidipine (4-9 mg/hr) was performed for 2 days when oral intake was difficult due to the decreased consciousness level, and from day 4, Olm $40 \mathrm{mg}$ and nifedipine $20 \mathrm{mg}$ were administered in combination. With the treatment of COVID-19, his blood pressure gradually stabilized, and the dose of nifedipine was reduced from Day 14 to $10 \mathrm{mg}$, and nifedipine was discontinued from Day 19 (Figure 2).

It took some more time for $\mathrm{SpO}_{2}$ to stabilize, but it eventually improved and the patient was discharged on Day 21 (Figure 2).

\section{Discussion}

Cases of COVID-19 often develop ischemic stroke, ischemic heart disease and venous thromboembolism. It has been reported that elevated D-D is a predictor of COVID-19 mortality (12), and that thrombi are frequently observed in pulmonary microarteries and pulmonary veins in autopsy cases (13). McGonagle et al. distinguished macrothrombosis and widespread microthrombosis in the lung from disseminated intravascular coagulation (DIC) and called it pulmonary intravascular coagulopathy (PIC) (14). Causes of the blood coagulation disorders in COVID-19 include hyperformation of neutrophil extracellular traps due to inappropriate release of nuclear chromatin from activated neutrophils that migrated and accumulated at the infected site, and subsequent platelet aggregation by their supplementation/activation $(15,16)$. Furthermore, it is known that elevation of Von Willebrand factor ( $\mathrm{vWF}$ ), which is derived from macrophages and monospheres or is activated by inflammatory cytokines (Interleukin-6, Tumor necrosis factor- $\alpha$, etc.), coagulation-inducing factors such as factors VII and VIII, and plasminogen activator inhibitor-I which suppresses urokinase-type or tissue plasminogen activator $(15,17)$, are involved in the pathogenesis. On the other hand, it has been reported that $\mathrm{vWF}$ and $\mathrm{P}$-selectin are released into the blood due to activation and damage of vascular endothelial cells, or that the loss of thrombomodulin, which is the center of the fibrinolytic system, causes microvascular thrombosis (18). Downregulation of ACE2 by SARS-CoV-2 binding inhibits the conversion of angiotensin II (AII) to angiotensin 1-7 $\left(\mathrm{AT}_{1-7}\right)$, resulting in an imbalance in the renin-angiotensin system. Reportedly, this results in further damage to vascular endothelial cells by AII, inflammation, promotion of oxidation, vasoconstriction, and coagulopathy mediated by an increase in plasminogen activator inhibitor-I (19-21). In this case, the patient's blood pressure, which was largely stable at the time of admission, was 
subsequently elevated. It has been suggested that Olm increases ACE2 and $\mathrm{AT}_{1-7}$, which binds to the Mas receptor to lower blood pressure and protect organs (22). Due to the fact that blood pressure control was stabilized by the treatment of COVID-19 (Figure 2e), we speculated that the ACE2 consumption by SARSCoV-2 might have made achievement of the antihypertensive effect of Olm via the Mas receptor difficult. On the other hand, the fact that blood pressure control was stabilized by the treatment of COVID-19 might suggest that direct vascular endothelial damage due to SARS-CoV-2 was progressing. In addition to the above-mentioned coagulopathy, the patient developed HPV disorder $(9,10)$, which, we speculated, together with emphysematous changes in the lungs, rapidly caused imbalance between ventilation and blood flow.

In this case, CT suggested pneumonia, which had multiple aggravating factors. Therefore, administration of Fav was started immediately after admission (Figure 2a). Fav selectively inhibits RNA-dependent RNA polymerase $(\mathrm{RdRp})$ by its metabolization and conversion to the active form favipiravir-ribofuranosyl triphosphate by an intracellular enzyme, which is recognized as a substrate for RdRp by RNA viruses (23). After the commencement of Fav treatment, the patient exhibited weakness and decrease in consciousness (tendency to somnolence), which improved after discontinuation of Fav. Chen et al. reported that $4.31 \%$ of patients receiving Fav had a psychiatric reaction (24), suggesting that these symptoms in our patient were likely to have been side effects of Fav. Subsequently, since fever persisted and the patient's $\mathrm{SpO}_{2}$ progressively decreased (Figure 2b), Rem was started on Day 4 (Figure 2a). Reportedly, Rem is phosphorylated in cells to a nucleic acid analog (triphosphate type remdesivir), which, like Fav, binds to RdRp and selectively inhibits it, thereby suppressing the growth of RNA viruses $(23,25)$. Its effectiveness against SARS-CoV-2 by this mechanism has also been reported (25-27). However, although CT suggested only slight exacerbation of pneumonia, our patient's fever persisted, $\mathrm{SpO}_{2}$ decreased, and CRP and D-D levels tended to increase even after the start of Rem (Figure 2a-d ). Therefore, Naf $100 \mathrm{mg}$ and Dex $6 \mathrm{mg}$ were also used from Day 8 (Figure 2a). Naf suppresses transmembrane protease serine 2 (TMPRSS2), an enzyme that cleaves and activates the spike protein, and blocks the invasion of SARS-CoV-2 into host cells $(23,28)$. It is used for the treatment of DIC and acute pancreatitis because it binds to the active center (serine) of enzymes, such as thrombin, XIIa, Xa, VIIa, kallikrein, plasmin and trypsin, and suppresses the coagulation/fibrinolytic system. Doi et al. have reported the efficacy of Naf $0.2 \mathrm{mg} / \mathrm{kg} / \mathrm{hr}$ in combination with Fav for COVID-19 when administered as a continuous intravenous infusion for an average of 14 days (29), but the optimal administration method has not yet been established. We were able to confirm a decrease in D-D levels after 4 days of administration of Naf with Rem at approximately the smallest dose $(0.07 \mathrm{mg} / \mathrm{kg} / \mathrm{hr})$ used in DIC (Figure 2d). Preliminary results from a large randomized controlled trial conducted in the United Kingdom showed that once-daily administration of $6 \mathrm{mg}$ Dex for up to 10 days resulted in a $35 \%$ reduction in mortality in patients with COVID-19 receiving invasive mechanical ventilation (30). On the other hand, the mortality rate in patients treated with Dex who received only oxygen support without invasive ventilatory management reduced by $20 \%$ (30). Corticosteroids (CS) are known to bind to cytoplasmic CS receptors and translocate to the nucleus, reducing the activity of pro-inflammatory transcription factors, such as nuclear factor of $\chi \mathrm{B}$ and activator protein-1, and to regulate transcription of anti-inflammatory genes (31). As a result, they reduce a number of inflammatory mediators involved in excessive cytokine responses (cytokine storms), although their effect on COVID-19 remains controversial $(32,33)$. Even in the large-scale randomized controlled trial mentioned above, no benefit of Dex administration to a group of patients with independent ventilation was recognized (31). Since CS affects the function of many immune cells and suppresses both innate and acquired immunity, smaller doses and shorter treatment durations are recommended (34). For this reason, we administered Dex $6 \mathrm{mg}$ once daily for 4 days using a decrease in CRP as an indicator of response to therapy, which proved to be successful (Figure 2a). Asakura et al. have demonstrated the concept of antiviral, anticytokine and anticoagulant combination therapy according to the stage of COVID-19 (35). In our case, the combination therapy was extremely effective within a short period of time, confirming its importance in the treatment of COVID-19.

The limitations of our report are that we did not confirm the histopathology of the lung and that since this was a case report, we cannot confirm that our therapy would be effective in all cases.

\section{Conclusion}


In COVID-19 patients with multiple comorbidities who have hypoxemia and coagulation abnormalities that are disproportionate to the severity of pneumonia on $\mathrm{CT}$, there is a high possibility that ventilation and blood flow imbalance due to PIC or HPV disorder has occurred. We believe it is important to commence antiviral and anticoagulant therapy as soon as possible, followed by use of a low dose of Dex for a short period to control cytokine hyperreactivity.

\section{Acknowledgements}

We also thank the patient for her permission to publish this manuscript. Furthermore, we thank medical editing services on Forte, Inc.

\section{Conflict of Interest}

None declared

\section{Author contributions}

N.K., A.M., K.H., T.K., T.A., G.T., H.M., and M.O. attended to the patient; N.K. wrote the manuscript; M.O. supervised management of the case and contributed to writing and editing the manuscript. All authors have read and approved the final manuscript.

\section{Ethics statement, consent for publication}

Patient consent was obtained from the patient for publication of this case report and any accompanying images.

\section{Availability of data and material}

Not applicable.

\section{References}

1. Epidemiology Working Group for NCIP Epidemic Response, Chinese Center for Disease Control and Prevention. The epidemiological characteristics of an outbreak of 2019 novel coronavirus diseases (COVID19) in China. Zhonghua Liu Xing Bing Xue Za Zhi. 2020;41(2):145-151.

2. Onder G, Rezza G, Brusaferro S. Case-fatality rate and characteristics of patients dying in relation to COVID-19 in Italy. JAMA. 2020;323(18):1775-1776.

3. $\mathrm{Wu} \mathrm{Z,} \mathrm{McGoogan} \mathrm{JM.} \mathrm{Characteristics} \mathrm{of} \mathrm{and} \mathrm{important} \mathrm{lessons} \mathrm{from} \mathrm{the} \mathrm{Coronavirus} \mathrm{Disease} 2019$ (COVID-19) outbreak in China: summary of a report of 72314 cases from the Chinese Center for Disease Control and Prevention. JAMA. 2020;323(13):1239-1241.

4. Hoffmann M, Kleine-Weber H, Schroeder S, et al. SARS-CoV-2 cell entry depends on ACE2 and TMPRSS2 and is blocked by a clinically proven protease inhibitor. Cell. 2020;181(2):271-280.

5. Hamming I, Timens W, Bulthuis ML, et al. Tissue distribution of ACE2 protein, the functional receptor for SARS coronavirus. A first step in understanding SARS pathogenesis. J Pathol. 2004;203(2):631-637.

6. Lukiw WJ, Pogue A, Hill JM. SARS-CoV-2 infectivity and neurological targets in the brain. Cell Mol Neurobiol. 2020;25:1-8.

7. Asselah T, Durantel D, Pasmant E, et al. COVID-19: Discovery, diagnostics and drug development. J Hepatol. 2021;74(1):168-184.

8. Bhatia P, Mohammed S. Severe hypoxemia in early COVID-19 pneumonia. Am J Respir Crit Care Med. 2020;202(4):621-622.

9. Siswanto, Gani M, Fauzi AR, et al. Possible silent hypoxemia in a COVID-19 patient: A case report. Ann Med Surg (Lond). 2020;60:583-586. 
10. Gattinoni L, Coppola S, Cressoni M, et al. COVID-19 does not lead to a "typical" acute respiratory distress syndrome. Am J Respir Crit Care Med. 2020;201(10):1299-1300.

11. Herrmann J, Mori V, Bates JHT, et al. Modeling lung perfusion abnormalities to explain early COVID-19 hypoxemia. Nat Commun. 2020;11(1):4883. doi: 10.1038/s41467-020-18672-6.

12. Shibata S, Arima H, Asayama K, et al. Hypertension and related diseases in the era of COVID-19: a report from the Japanese Society of Hypertension Task Force on COVID-19. Hypertens Res. 2020;43(10):10281046 .

13. Fox SE, Akmatbekov A, Harbert JL, et al. Pulmonary and cardiac pathology in African American patients with COVID-19: an autopsy series from New Orleans. Lancet Respir Med. 2020;8(7):681-686.

14. McGonagle D, O'Donnell JS, Sharif K, et al. Immune mechanisms of pulmonary intravascular coagulopathy (PIC) in COVID-19 pneumonia. Lancet Rheumatol. 2020;2(7):e437-e445.

15. Lee C, Choi WJ. Overview of COVID-19 inflammatory pathogenesis from the therapeutic perspective. Arch Pharm Res. 2021. https://doi.org/10.1007/s12272-020-01301-7.

16. Jiménez-Alcázar M, Rangaswamy C, Panda R, et al. Host DNases prevent vascular occlusion by neutrophil extracellular traps. Science. 2017;358(6367):1202-1206.

17. Tang N, Li D, Wang X, et al. Abnormal coagulation parameters are associated with poor prognosis in patients with novel coronavirus pneumonia. J Thromb Haemost. 2020;18(4):844-847.

18. O'Sullivan JM, McGonagle D, Ward SE, et al. Endothelial cells orchestrate COVID-19 coagulopathy. Lancet Haematol. 2020;7:e553-e555.

19. Henry BM, Vikse J, Benoit S, et al. Hyperinflammation and derangement of renin-angiotensin-aldosterone system in COVID-19: A novel hypothesis for clinically suspected hypercoagulopathy and microvascular immunothrombosis. Clinica Chimica Acta. 2020;507:163-173.

20. Gan R, Rosoman NP, Henshaw DJE, et al. COVID-19 as a viral functional ACE2 deficiency disorder with ACE2 related multi-organ disease. Medical Hypotheses. 2020;144:1-7.

21. Kasal DA, De Lorenzo A, Tibiriçá E. COVID-19 and microvascular disease: Pathophysiology of SARSCoV-2 infection with focus on the renin-angiotensin system. Heart Lung Circ. 2020;29(11):1596-1602.

22. Furuhashi M, Moniwa N, Mita T, et al. Urinary angiotensin-converting enzyme 2 in hypertensive patients may be increased by olmesartan, an angiotensin II receptor blocker. Am J Hypertens. 2015;28(1):15-21.

23. Hosoki K, Chakraborty A, Sur S. Molecular mechanisms and epidemiology of COVID-19 from an allergist's perspective. J Allergy Clin Immunol. 2020;146(2):285-299.

24. Chen C, Zhang Y, Huang J, et al. Favipiravir versus Arbidol for COVID-19: A randomized clinical trial. medRxiv 2020; doi:https://doi.org/10.1101/2020.03.17.20037432.

25. Frediansyah A, Nainu F, Dhama K, et al. Remdesivir and its antiviral activity against COVID-19: A systematic review. Clin Epidemiol Glob Health. 2021;9:123-127.

26. Singh AK, Singh A, Singh R, et al. Remdesivir in COVID-19: A critical review of pharmacology, preclinical and clinical studies. Diabetes Metab Syndr. 2020;14(4):641-648.

27. Hillaker E, Belfer J, Bondici A, et al. Delayed initiation of remdesivir in a COVID-19-positive patient. Pharmacotherapy. 2020; doi:10.1002/phar.2403.

28. Hoffmann M, Schroeder S, Kleine-Weber H, et al. Nafamostat mesylate blocks activation of SARS-CoV-2: new treatment option for COVID-19. Antimicrob Agents Chemother. 2020;64(6):e0075420.doi:10.1128/AAC.00754-20. 
29. Doi K, Ikeda M, Hayase N, et al.; COVID-UTH Study Group. Nafamostat mesylate treatment in combination with favipiravir for patients critically ill with Covid-19: a case series. Crit Care. 2020;24(1):392.doi:10.1186/s13054-020-03078-z.

30. RECOVERY Collaborative Group, Horby P, Lim WS, Emberson JR, et al. Dexamethasone in hospitalized patients with Covid-19. N Engl J Med. 2021;384(8):693-704.

31. Brattsand R, Linden M. Cytokine modulation by glucocorticoids: mechanisms and actions in cellular studies. Aliment Pharmacol Ther. 1996;10 (Suppl. 2):81-90 discussion 1-2.

32. Shang L, Zhao J, Hu Y, et al. On the use of corticosteroids for 2019-nCoV pneumonia. Lancet. 2020;395 (10225):683-684.

33. Russell CD, Millar JE, Baillie JK. Clinical evidence does not support corticosteroid treatment for 2019nCoV lung injury. Lancet. 2020;395 (10223):473-475.

34. Youssef J, Novosad SA, Winthrop KL. Infection risk and safety of corticosteroid use. Rheum Dis Clin N Am. 2016;42(1):157-176.

35. Asakura H, Ogawa H. COVID-19-associated coagulopathy and disseminated intravascular coagulation. Int J Hematol. 2021;113(1):45-57.

\section{Hosted file}

image1.emf available at https://authorea.com/users/424553/articles/529626-covid-19-withrapid-progression-to-hypoxemia-likely-due-to-imbalance-between-ventilation-and-bloodflow-a-case-report

\section{Hosted file}

image2.emf available at https://authorea.com/users/424553/articles/529626-covid-19-withrapid-progression-to-hypoxemia-likely-due-to-imbalance-between-ventilation-and-bloodflow-a-case-report

\section{Figure Legends}

Figure 1 Chest computed tomography images

a: Image taken on Day 1 showing emphysematous changes in the lung field and ground-glass-like shadows with unclear borders below the dorsal pleura of the upper right lobe. b: Image taken on Day 7 showing slight exacerbation of the ground-glass shadows. C: Image taken on Day 13 showing improvement in the ground-glass shadows.

Figure 2 Clinical course of the patient

a: The black dots indicate changes in body temperature and dotted lines indicate respiratory rate. The white inverted triangle indicates $3600 \mathrm{mg}$ favipiravir administration. The long downward-pointing black arrow indicates administration of $200 \mathrm{mg}$ remdesivir, and the short downward-pointing black arrows indicate administration of $100 \mathrm{mg}$ remdesivir. The horizontal white bars indicate continuous intravenous infusion of nafamostat mesilate $0.07 \mathrm{mg} / \mathrm{kg} / \mathrm{hr}$. The black inverted triangles indicate administration of $6 \mathrm{mg}$ dexamethasone. b: The transition of $\mathrm{SpO}_{2}$. The horizontal black bars indicate the flow rate of oxygen administered via a nasal cannula. The white circles indicate the day when CT was performed, and the black stars indicate the days when confirmatory blood gas analyses were performed. c: The transition of C-reactive protein (CRP) level. d: The transition of D-dimer (D-D) levels. e: The transition of systolic blood pressure at the top and diastolic blood pressure at the bottom part of the graph. The horizontal light-gray bar indicates administration of olmesartan, the moderately-dark gray bar indicates continuous intravenous infusion of pernidipine, and the dark gray bar indicates administration of nifedipine. 
BP, blood pressure; BT, body temperature; CRP, C-reactive protein; D-D, D-dimer; RR, respiratory rate; $\mathrm{SpO}_{2}$, peripheral oxygen saturation on pulse oximetry.

\section{Hosted file}

Figure1.pptx available at https://authorea.com/users/424553/articles/529626-covid-19-withrapid-progression-to-hypoxemia-likely-due-to-imbalance-between-ventilation-and-bloodflow-a-case-report

\section{Hosted file}

Figure2.pptx available at https://authorea.com/users/424553/articles/529626-covid-19-withrapid-progression-to-hypoxemia-likely-due-to-imbalance-between-ventilation-and-bloodflow-a-case-report 